High-resolution topographical information improves tree-level storm damage models

\title{
Suvanto, Susanne
}

2018-06

Suvanto , S , Henttonen , H M , Nöjd , P \& Mäkinen, H 2018 , ' High-resolution topographical information improves tree-level storm damage models ' , Canadian Journal of Forest Research , vol. 48 , no. 6 , pp. 721-728 . https://doi.org/10.1139/cjfr-2017-0315

http://hdl.handle.net/10138/307294

https://doi.org/10.1139/cjfr-2017-0315

unspecified

acceptedVersion

Downloaded from Helda, University of Helsinki institutional repository.

This is an electronic reprint of the original article.

This reprint may differ from the original in pagination and typographic detail.

Please cite the original version. 
Title

4 High-resolution topographical information improves tree-level storm damage models

\section{Authors}

6 Susanne Suvanto ${ }^{1,3}$, susanne.suvanto@luke.fi (Corresponding author)

7 Helena M. Henttonen ${ }^{1}$, helena.henttonen@luke.fi

$8 \quad$ Pekka Nöjd ${ }^{2}$, pekka.nojd@,luke.fi

$9 \quad$ Harri Mäkinen ${ }^{2}$, harri.makinen@,luke.fi

\section{Affiliations and addresses}

$11{ }^{1}$ Natural Resources Institute Finland (Luke), Bioeconomy and Environment, Latokartanonkaari

129 9, 00790 Helsinki, Finland

$13{ }^{2}$ Natural Resources Institute Finland (Luke), Production systems, Tietotie 2, 02150 Espoo,

14 Finland

$15{ }^{3}$ University of Helsinki, Department of Geosciences and Geography, P.O. Box 64, FI-00014

16 University of Helsinki, Finland 


\section{Abstract}

18 Storms cause major forest disturbances in Europe. The aim of this study was to model tree-level

19 storm damage probability based on the properties of tree and its environment and to examine

20 whether fine-scale topographic information is connected to the damage probability. We used data

21 documenting effects of two autumn storms on over 17000 trees on permanent Finnish National

22 Forest Inventory plots. The first storm was associated with wet snow fall that damaged trees,

23 while exceptionally strong winds and gusts characterized the second storm. During the storms

24 soils were unfrozen and deciduous trees without leaves. Generalized linear mixed models were

25 used to study how topographical variables calculated from digital elevation models (DEM) with

26 resolutions of 2 and $10 \mathrm{~m}$ (TOPO2 and TOPO10) were related to damage probability, in addition

27 to variable groups for tree (TREE) and stand (STAND) characteristics. We compared models

28 containing different variable groups with Akaike Information Criteria. The best model contained

29 variable groups TREE, STAND and TOPO2. Increase in slope steepness calculated from the

30 high-resolution DEM decreased tree-level damage probability significantly in the model. This

31 suggests that the local topography affects the tree-level damage probability and that high-

32 resolution topographical data improves the tree-level damage probability models.

33 Keywords: windthrow, wind storm, wind damage, snow damage, digital elevation model 


\section{Introduction}

35 Changes in climate are expected to have pronounced effects on the disturbance regime of boreal

36 forests (Seidl et al. 2017). In Europe, storms account for a larger amount of forest damage than

37 other disturbance types (Schelhaas et al. 2003), and storm induced damage has increased in

38 Europe over the last 60 years (Gregow et al. 2017). Understanding storm disturbance processes is

39 crucial for predicting climate change effects on forests, as climate induced changes in forest

40 productivity are altered by disturbances (Lindroth et al. 2009, Reyer et al. 2017).

41 Wind damage probability of a tree is affected by its susceptibility to damage and the wind

42 conditions subjected to it. As wind conditions during storms can have high spatial variance, the

43 data about the local wind conditions affecting trees can be difficult to obtain. Local wind

44 conditions are modified by forest management operations, such as thinnings and clear cuttings,

45 in which trees in previously sheltered environments are exposed to stronger winds (Peltola et al.

46 1999, Jalkanen and Mattila 2000). Local variation in wind properties is also influenced by

47 topography, and therefore topographical variables have often been included in statistical models

48 of wind damage (e.g., Laiho 1987, Schmidt et al. 2010, Albrecht et al. 2012, Schindler et al.

49 2012). Suvanto et al. (2016) showed that, when detailed data about the wind conditions during

50 the storms are not available, stand-level storm damage models can be improved by adding

51 topographical variables derived from digital elevation models (DEM), when used in combination

52 with estimated wind direction. Topographical information can also be included in storm damage

53 models indirectly through wind field data, as near-surface wind characteristics are strongly

54 dependent on topography. For example, Jung and Schindler (2016) and Venäläinen et al. (2017)

55 utilized topographical data in developing high resolution wind speed data set for studying forest

56 wind damage risk. 
57 Tree susceptibility to damage is affected by properties such as tree species, size and shape.

58 Probability of wind damage has been found to increase with increasing tree height (Lohmander

59 and Helles 1987, Schmidt et al. 2010, Albrecht et al. 2012) and tall trees with relatively small

60 diameter are particularly vulnerable to damage (Peltola et al. 1999). Norway spruce (Picea abies

61 (L.) Karst) is considered more vulnerable to wind damage than Scots pine (Pinus sylvestris L.)

62 (Peltola et al. 1999, Dobbertin 2002, Valinger and Fridman 2011), as its relatively shallow root

63 system provides a weaker anchorage to the ground (Kalela 1949, Peltola et al. 2000). On the

64 other hand, Scots pine has been found to be more vulnerable to snow damage than Norway

65 spruce, due to differences in the crown shape between the species (Nykänen et al. 1997). In

66 northern Europe, deciduous species have a lower risk of wind damage compared to evergreen

67 conifers, because most storms and the strongest winds occur during autumn and winter when

68 deciduous trees have already shed their leaves and have therefore lower wind loads (Peltola et al.

69 1999). Pathogens that cause wood decay and weaken trees predisposing them to abiotic damage

70 (Whitney et al. 2001, Honkaniemi et al. 2017).

71 Rapidly developing remote sensing methods provide increasingly detailed information about the

72 physical environment, including fine-scale topography. The National Land Survey of Finland

73 (NLS) is conducting a country-wide laser scanning campaign, and the resulting data is used for

74 creating a new 2 meter resolution DEM, which will cover the whole country by 2020 (NLS

75 2017a). Country-wide laser scanning data sets are being produced in other countries as well (e.g.

76 Lantmäteriet 2017, Swisstopo 2017). In studies of forest storm damage, these data sets provide

77 increased accuracy but also enable to consider thefine-scaled variation in topography within the

78 close vicinity of the studied trees. While there are some examples of using fine-scale

79 topographical data for studying wind damage in forests (see Saarinen et al. 2016), most studies 
80 have used coarser data to account for topographical variation (e.g., Schmidt et al. 2010, Anyomi

81 and Ruel 2015, Suvanto et al. 2016) or excluded topographical variables from the analysis (e.g.,

82 Valinger and Fridman 2011).

83 The aim of this study was (1) to statistically model the damage probability of an individual tree

84 during storms based on the properties of a tree and its environment and (2) to examine whether

85 fine-scale topographic information is connected to tree-level storm damage probability. To

86 accomplish this, we used an extensive empirical data set documenting damage to trees after two

87 severe autumn storms in 2001, and studied how tree and stand properties, as well as fine-scale

88 and coarse-scale topographical variables were connected to damage probability of trees.

\section{2. Material and methods}

$90 \quad 2.1$ Storm damage data

91 The storm damage data set was collected between November 2001 and January 2002 at

92 permanent plots of the Finnish National Forest Inventory (NFI) after two exceptionally severe

93 autumn cyclones Pyry (1.11.2001) and Janika (15.11.2001) (Fig. 1). The storms caused an

94 estimated damage of 7.3 million cubic meters of stemwood (Ihalainen and Ahola 2003). Of the

95 two storms, storm Janika was associated with stronger winds, average wind speed (10 minutes)

96 ranging between 16 to $18 \mathrm{~ms}^{-1}$ and strongest measured gusts in land areas reaching $27.8 \mathrm{~ms}^{-1}$.

97 These were the highest wind speeds measured in land-areas in Finland since autumn 1959 (FMI

98 2001). Storm Pyry had lower wind speeds (in the study area, measured maximum 10 minute

99 average wind speeds up to $12 \mathrm{~ms}^{-1}$ and gusts up to $21.9 \mathrm{~ms}^{-1}$ in land areas, higher close to the sea

100 or large lakes) but was associated with wet snowfall that damaged trees. Snow fall related to

101 storm Pyry lasted three days (30.10.-2.11.2001). The snow load on tree crowns during Pyry was 
102 estimated to $30 \mathrm{~kg} \mathrm{~m}^{-2}$ (Zubizarreta-Gerendiain et al. 2012). Soils were unfrozen and broad103 leaved trees without leaves during both storms (Ihalainen and Ahola 2003).

104 In the study area, NFI follows a cluster sampling design where clusters are arranged in a grid. 105 Every fourth cluster in the $9^{\text {th }}$ National Forest Inventory in Finland (NFI9) was a permanent 106 cluster containing 10 or 14 plots (Tomppo et al. 2011). On permanent clusters the tree locations 107 on plots were mapped, which enabled the identification of trees in a re-measurement conducted 108 after the storms in 2001. The trees included in plots were selected using angle count sampling 109 with basal area factor 2 and maximum radius of $12.52 \mathrm{~m}$ (Tomppo et al. 2011).

110 The storm damage data covers a total of 1826 NFI9 plots in altogether 276 NFI9 permanent 111 clusters in southern and western Finland, and includes a total of 17686 trees of which 220 had 112 been damaged in the storms (Fig. 1, Ihalainen and Ahola 2003, Suvanto et al. 2016). However, 113 we excluded standing trees classified as dead or dying in the NFI9 measurement (287 trees), as 114 well as conifers other than Norway spruce and Scots pine (18 trees). The high-resolution digital 115 elevation model was not available for the whole study area and trees located in the areas of 116 missing data were excluded from the analysis (804 trees). Therefore, the final data set contained 11716577 trees (of which 202 were damaged) in 1730 NFI9 plots within 267 clusters (Table 1). 118 Different types of storm caused damage were represented in the data set. Most common damage 119 types in the data were uprooting (42 pines, 79 spruces and 4 deciduous trees) and stem breakage 120 (25 pines, 12 spruces and 6 deciduous trees). The rest of the damaged trees were classified as 121 leaning trees (10 pines and 9 spruces), damaged standing trees (2 spruces) or damaged trees that 122 had already been removed and damage type could not be determined ( 3 pines, 9 spruces and 1 123 deciduous tree). 
124 Variables describing stand and tree characteristics were extracted from the storm damage data as

125 well as from the NFI9 data collected at the plots before the storms (1996 to 1999). Stand-level

126 variables included stand age, basal area (BA), type and timing of recent management operations,

127 soil type, presence of decayed standing trees in the stand and presence of new open area within

12840 meters from the plot center (estimated by the field crew). Only open stand borders in the

129 direction of the storm wind were considered and borders towards permanently open areas, such

130 as lakes and agricultural fields, were not considered. Forest management variables included

131 information about the type of the cutting (thinning or regeneration cutting) and the time of the

132 cutting (last five or last ten years). As clear-cut stands were excluded, regeneration cuttings

133 contained seed and shelter tree cuttings that leave 30 to 300 stems per hectare.

134 Tree-level variables included tree species, tree height, stem diameter at breast height $(1.3 \mathrm{~m}$,

$135 \mathrm{DBH}$ ), relative DBH (the ratio between DBH and the stand average DBH), and height-to-DBH

136 ratio. Tree height was measured in the field only for every seventh tree in each plot. For the rest

137 of the trees we used height predictions based on a model by Eerikäinen (2009), which uses DBH,

138 tree species, and site and stand properties as predictors.

139 We attempted to account for the spatial variation in storm severity by using meteorological data

140 from the storms, i.e. maximum wind speeds in storm Janika and snow accumulation in storm

141 Pyry. However, as the spatial resolution of the available data was low and it was not possible to

142 separate the occurred damage in the data between the two storms, these variables were left out of

143 the final analysis. Insufficiency of coarse scale weather data in predicting storm damage has been

144 shown before, for example, by Schindler et al. (2009). 


\subsection{Topographical variables}

146 In the study area, elevation ranges from the sea level to 229 meters above sea level. Elevation

147 increases gradually with distance from the sea and local variations in elevation are relatively low:

148 average difference in elevation between a tree location and its surroundings within one kilometer

149 radius was 5.1 meters while maximum difference was 44.3 meters. Variables describing the

150 topography in the neighborhood of the trees were calculated from the NLS digital elevation

151 models in two resolutions: $2 \mathrm{~m}$ (DEM2) and $10 \mathrm{~m}$ (DEM10). DEM2 is based on NLS laser

152 scanning data with a point density of at least 0.5 points per square meter, whereas DEM10 is

153 produced with contour lines, ground surface points digitized in a stereo workstation environment

154 and elevational information in the objects of NLS Topographical database. The elevation 155 accuracy is 0.3 meters in DEM2 and 1.4 meters in DEM10 (NLS 2017a, NLS 2017b). The laser 156 scanning data used for producing DEM2 has been collected after the studies storms in year 2001

157 and, therefore, it could not be used for extracting information about tree characteristics in this 158 study.

159 From both DEMs slope angle and direction as well as topographic position index (TPI) with 160 different radii (10, 20 and $30 \mathrm{~m}$ for DEM2 and 50, 100, 150, 500 and $1000 \mathrm{~m}$ for DEM10) were 161 calculated with the R package raster (Hijmans 2016). TPI describes the relative topographical 162 position of a location in relation to its surroundings and is calculated as a difference of elevation 163 in a location to the mean elevation within a defined radius (Guisan et al. 1999, Gallant and 164 Wilson 2000). Negative values of TPI mean that a location is at lower elevation than its 165 surroundings, and thus better shelter from wind, whereas positive values indicate locations 166 higher than their surroundings, and thus higher wind exposure. 
167 Values from all topographic variables were extracted for each tree location. To reduce the error

168 in the tree locations, coordinates of the midpoints of the permanent NFI plots were taken from

169 the more recent $11^{\text {th }}$ NFI (2009-2013) with more accurate positioning of the plots. To account for

170 uncertainty in the positioning of the tree locations, a mean (median for slope direction) of the

171 neighboring cells, with cell center within a three meter radius from the tree location, was used for

172 variables calculated from DEM2. Slope direction was transformed into a class variable 173 describing whether the slope was directed towards the storm wind or sheltered from it (using 174 wind direction $337.5^{\circ}$ as the main wind direction of the storms was north to north-west. Detailed 175 data of the near-surface wind direction was not available). If slope steepness was lower than $1^{\circ}$ 176 slope direction was set to wind side (Fig. 2).

\section{2.4 Statistical methods}

178 Storm damage probability of an individual tree was modeled with a mixed effects logistic model, 179 where the response variable described whether or not a tree was damaged in the storms $(0 / 1)$. 180 The model was fitted in SAS (version 9.4, SAS Institute Inc. 2017) using procedure GLIMMIX. 181 Random effects were used to account for the hierarchical structure of the data, resulting from the 182 clustered sampling design of the NFI. Two-level nested random effects were used for the 183 intercepts, as trees were located in plots and plots in clusters.

184 In the $9^{\text {th }} \mathrm{NFI}$, the maximum radius of angle count plots was restricted to 12.52 meters. In angle 185 count plots sampling probability is proportional to the basal area of a tree. However, as plot 186 radius was restricted, large trees with a DBH larger than $35.4 \mathrm{~cm}$ were underrepresented in the 187 data. Therefore, multi-level weights were used in the model to have the representation of tree 188 sizes match an unrestricted angle count plot. The inverse value of the difference in tree sampling 189 probability between an ordinary angle count plot and the restricted diameter angle count plot was 
190 used in calculating tree-level weights. Thus, trees with diameter less than $35.4 \mathrm{~cm}$ were assigned

191 weight 1 , while for larger trees the weight calculated as $1 /\left(\mathrm{A}_{\text {restricted }} / \mathrm{A}_{\text {unrestricted }}\right)$, where $\mathrm{A}_{\text {restricted }}$

192 was the area of the $12.52 \mathrm{~m}$ radius plot and $\mathrm{A}_{\text {unrestricted }}$ was the DBH dependent area from which

193 tree would have been included in an angle count plot if the plot radius was not restricted. The

194 weights were then scaled by setting the sum of weights within each plot to correspond to the

195 actual number of measured trees in the plot, following the "method 2" in Pfeffermann et al.

196 (1998) and Rabe-Hesketh and Skrondal (2006). On plot and cluster levels all observations were

197 given weight 1.

198 The independent variables were divided into five variable groups containing variables related to

199 tree characteristics (TREE), stand characteristics (STAND) and topographic characteristic

200 calculated from two different resolution DEMs (TOPO2 and TOPO10). All continuous

201 independent variables were scaled to have a mean of 0 and standard deviation of 1 (Table 3).

202 Thus, the model intercept is interpreted as the expected value when all the continuous predictor

203 variables are set to their means and the coefficient estimates between predictor variables are

204 more comparable to each other. A logarithm transformation was tested for all continuous

205 variables by comparing models with and without transformation with Akaike Information

206 Criteria (AIC, Akaike 1974).

207 Collinearity between independent variables in the final variable groups was checked with

208 Pearson product-moment correlation coefficients between continuous variables. The correlations

209 were well below 0.7 except for the correlation between slope steepness values calculated from

210 DEM2 and DEM10 $(r=0.73, p<0.001)$. When the variables were log-transformed, all the

211 correlations were below 0.7. 
212 In a preliminary model selection variables were first chosen based on a priori knowledge of

213 factors affecting storm damage. Different combinations of variables were then tested and

214 variables were excluded from the variable groups if they showed small effect sizes (i.e., had

215 negligible effect on damage probability in the model), counterintuitive coefficient signs (for

216 example, if damage probability were to decrease with increasing wind exposure) or had large p-

217 values. In addition, AIC values of models with and without a variable were compared before a

218 decision was made to exclude variables.

219 Models were fitted with different combinations of variables groups (TREE, STAND, TOPO2,

220 TOPO10) and then compared using AIC, AIC weights $\left(w_{i}\right)$, as well as receiver operating

221 characteristic (ROC) curves and area under curve values (AUC). AIC measures the relative

222 quality of the model, so that lower values of AIC indicate a better model. AIC weights were also

223 calculated for the models. The weights add up to 1 for the considered set of models and are

224 interpreted as the weight of evidence in favor of a model being the Kullback-Leibler best model,

225 assuming that one of the considered models is the best model (Burnham and Anderson 2002).

226 ROC curves and AUC values describe the model's ability to discriminate between damage

227 events and non-events (see Hosmer et al. 2013).

\section{3. Results}

229 In the preliminary model building process several candidate variables were left out of the

230 models. From the TREE variable group DBH, relative DBH and height-to-DBH ratio were

231 excluded and species were grouped to a two-class variable separating coniferous and deciduous

232 species. Stand age, stand basal area, soil type and timing of the last cuttings were left out from

233 the STAND variable group. In addition, type of last cutting was grouped into only two classes 
234 where regeneration cutting (for example seed or shelter tree cutting) formed one class and 235 thinning and no cuttings formed another class. In the TOPO groups the topographic position 236 index (TPI) variables as well as the interaction between slope steepness and direction were left 237 out of the final models. The meteorological variables describing the storm conditions were not 238 included in the models, as they were not statistically significant and had illogical, negative 239 coefficients (results not shown). The variables included in the variable groups that were used in 240 the final model comparisons are described in Table 2.

241 The best model, chosen by ranking the alternative models by AIC, contained variable groups 242 describing tree and stand properties and fine-scale topographical information (TREE+STAND+ 243 TOPO2, Table 4). The AIC weight $\left(w_{i}\right)$ for the TREE+STAND+TOPO2 model was clearly 244 higher than for the other models. The second ranked model in the AIC comparison also 245 contained TOPO2 variable group (model TREE+STAND+TOPO2+TOPO10, Table 4). In 246 TOPO2 and TOPO10 variable groups slope steepness (SLOPE) had a negative coefficient, 247 implying a decreasing damage probability in steeper slopes (Table 5, only shown for the first 248 ranked model).

249 TREE variables (conifer/deciduous species and height) were the most important single group 250 accounting for damage probability. The other models with only one variable group (TOPO2, 251 STAND, TOPO10) were last in the AIC comparison, with AIC weights close to 0 and low AUC 252 values (Table 4). The coefficients of variables in the TREE group showed an increasing damage 253 probability with increasing tree height for conifers, and lower damage probability, as well as 254 decreasing damage probability with tree height, for deciduous trees (Table 5).

255 The STAND variable group was included in the best model with the lowest AIC (Table 4). 256 Model coefficients showed higher damage probability in the proximity of new open stand 
257 borders (OPENAREA) and in stands where regeneration cuttings had been made within ten years 258 (from NFI9 measurement).

259 For the models ranked highest, the AUC values, which describe the models ability to 260 discriminate between damage and non-damage events, were slightly under 0.7 , which is often

261 taken as a threshold of acceptable discrimination (Table 4, Fig. 3). The best model to reach the

2620.7 threshold was TREE + STAND + TOPO2, and similar AUC values were found for other top 263 models of the AIC comparison. The lowest AUC values were found for one variable group 264 models TOPO2 and TOPO10 (Table 4).

\section{4. Discussion}

266 Our results demonstrate that the high-resolution topographical data, describing local variations in 267 topography, provides useful information about the storm damage probability of trees. Fine-scale 268 topographical variables proved to work better than variables calculated from the coarser scale 269 DEM. Using high-resolution data with high elevation accuracy is useful especially in tree-level 270 studies, where it can be used to characterize the local neighborhood of a tree in detail. However, 271 understanding the fine-scaled factors driving tree-level vulnerability to damage is also important 272 for larger scale studies, as shown by Seidl et al. (2014) who found that neglecting spatial and 273 structural within-stand heterogeneity weakened the outcome of wind disturbance models.

274 The use of laser scanning data as a source for elevation models not only enables the 275 improvement of data resolution but also improves the accuracy of the data. Due to the difference 276 in methods in creating the elevation models the high-resolution DEM2 has significantly better 277 elevation accuracy than the older DEM10. This in part also explains the better performance of 278 variables calculated from DEM2 in the storm damage models. 
279 Not all studies have found topography to be useful in modeling storm damage. Albrecht et al. 280 (2012) gave three possible explanations for why topography was not found to affect damage

281 probability in their study: (1) variables describing stand and tree characteristics were superior to 282 geographical conditions such as topography, (2) the used variables were not suitable for 283 describing the conditions affecting damage probability, and (3) the data set did not contain 284 extremely exposed sites where the effect of topography would have been clear. While the two 285 first explanations are in line with our results, the third one is not supported by our results. The 286 results showed that topography was connected to storm damage probability, even though our 287 study area is characterized by a gentle topography with only small variations in elevation. This is 288 in contrast with some previous studies suggesting that non-significant effect of topography was 289 caused by low topographic variation of the study area (Anyomi and Ruel 2015, Saarinen et al. 290 2016).

291 The choice of variables calculated from DEMs is crucial for effectively describing the local wind 292 conditions. In addition to topographical variables included in this study effects of topography on 293 wind conditions have been described with different indices, such as distance-limited 294 topographical exposure (TOPEX), which is calculated as sum of maximum angle to the ground 295 in eight directions (Quine and White 1998, Scott and Mitchell 2005). The used spatial scale may 296 also influence the functioning of the used variables. While the interaction of slope steepness and 297 slope direction was found to significantly affect stand-level damage probability in another study 298 using the same data set as used here (Suvanto et al. 2016), only slope steepness was significant in 299 this tree-level study. Slope direction calculated from a high-resolution DEM may vary locally a 300 lot (Fig. 2) and therefore may not describe well the location's exposure to wind. The significant 301 effect of slope steepness may be related to locations with high slope steepness being associated 
302 with more variable topography in general, and being therefore more sheltered from wind. In 303 addition, high-resolution slope steepness may be correlated to other variables than wind that are 304 related to storm damage. For example, topography is related to soil properties, which in turn 305 affect the support trees have against uprooting (Peltola et al. 1999).

306 While fine-scale topographical variables were included in the model with lowest AIC, they did 307 not perform well alone (i.e., the TOPO2 model in Table 4). Instead, the results show that of the 308 studied variable groups, tree properties are most clearly linked to storm damage probability, as 309 the TREE model had clearly lower AIC values, higher AIC weights and higher AUC values 310 compared to the other models with only one variable group (Table 4). Similar results 311 emphasizing the importance of tree species and height have been reported in previous studies 312 (Lohmander and Helles 1987, Schmidt et al. 2010, Albrecht et al. 2012).

313 The TREE variable group consisted of tree species group (conifer or deciduous), tree height, and 314 interaction term of these two. Norway spruce and Scots pine were grouped into one class as their 315 difference was not significant in the models. Previous studies have shown differences between 316 the species (Nykänen et al. 1997, Dobbertin 2002, Valinger and Fridman 2011). However, the 317 storm damage in our data set contained both wind and snow related damage. This may have 318 reduced the difference between the two conifer species, as spruce is considered to be more 319 vulnerable to wind and the crown shape of pines may expose them to snow damage. It is also 320 possible that the damaged deciduous trees in the data have been mostly damaged by snow, as the 321 damaged deciduous trees were smaller than average (Table 1) and model results for deciduous 322 trees showed decreasing damage probability with tree height, which is atypical for wind damage.

323 The STAND variable group showed increased damage probability in stands after regeneration 324 cuttings, which in this data are seed and shelter tree cuttings that leave 30 to 300 stems per 
325 hectare to the stand. Increased damage probability was also found for trees close to open stand

326 borders (OPENAREA variable). This effect results from increased wind load after the cutting or

327 at newly created stand border on trees that have not been acclimated to strong winds (Lohmander

328 and Helles 1987, Peltola et al. 1999, Jalkanen and Mattila 2000). The model also showed

329 increased damage risk of trees in stands where decay in living trees had been documented. Wood

330 decay decreases stem strength and tree anchorage and, therefore, increases the vulnerability of

331 the tree to wind damage (Honkaniemi et al. 2017). Stand level information about decay was

332 selected in this study instead of tree-level information because wood-decay in living trees is

333 difficult to detect in the field (Mattila and Nuutinen 2007). Yet, if there are trees in the stand that

334 are visibly affected by wood-decaying fungi (e.g. Heterobasidion sp.) the probability of decay in

335 other trees in the same stand is also higher.

336 The location accuracy of the trees is a source of uncertainty in the topographical variables as

337 there is necessarily some error involved in the GPS positioning of the NFI plots. In this study, we

338 aimed to control this effect by calculating the high-resolution topographical variables as the

339 average values of grid cells within three meters from the tree location. Yet, it is still likely that

340 inaccuracy in the tree locations causes uncertainty to the DEM2 variables.

341 The statistical significance of individual variables is affected by the size of the data set. Even

342 though the data set is large, the proportion of damaged trees was rather low $(\sim 1.2 \%$ of the data)

343 in comparison with many other studies (e.g., Schmidt et al. 2010, Kamimura et al. 2016). A

344 larger data set, especially a larger number of damaged trees, would be useful in specifying the

345 factors affecting damage probability.

346 Our results demonstrate the connection between fine-scaled topographical variation in a tree's

347 neighborhood and the storm damage probability of a tree. Topography affects tree damage 
348 probability indirectly, through its effects on other factors such as wind and soil characteristics.

349 Thus, the effects of fine-scaled topography should be taken into account in calculation of these

350 variablles, as most of the available data sets are based on input data of coarser resolution than the

351 DEMs used in this study (e.g., Jung and Schindler 2016, Venäläinen et al. 2017). When high-

352 resolution topographical information is available, it should be considered in future studies of

353 storm damage in forests, either as topographical variables or as an inputs for variables describing

354 the direct factors affecting the damage probability.

\section{Acknowledgements}

356 The study was conducted in the Natural Resources Institute Finland (Luke). The work was

357 supported by personal grant to SS from the Finnish Society of Forest Research and grants from 358 Academy of Finland (No. 257641, 265504 and 288267). We would like to thank Antti Ihalainen 359 and the whole NFI team for the storm damage data set and Juho Pitkänen (Luke) for providing 360 the tree height predictions for the NFI tally trees.

\section{$361 \quad$ References}

362 Akaike, H. 1974. A new look at the statistical model identification. IEEE Trans. Autom. Control 363 19: $716-723$.

364 Albrecht, A., Hanewinkel, M., Bauhus, J., and Kohnle, U. 2012. How does silviculture affect 365 storm damage in forests of south-western Germany? Results from empirical modeling based 366 on long-term observations. Eur. J. For. Res. 131: 229-247. 
367 Anyomi, K.A., and Ruel, J. 2015. A multiscale analysis of the effects of alternative silvicultural 368 treatments on windthrow within balsam fir dominated stands. Can. J. For. Res. 45: 1739$369 \quad 1747$.

370 Burnham, K.P., and Anderson, D.R. 2002. Model selection and multimodal inference: a practical 371 information-theoretic approach. Springer-Verlag, New York.

372 Dobbertin, M. 2002. Influence of stand structure and site factors on wind damage comparing the 373 storms Vivian and Lothar. For. Snow Landsc. Res. 77: 187-205.

374 Eerikäinen, K. 2009. A multivariate linear mixed-effects model for the generalization of sample 375 tree heights and crown ratios in the Finnish National Forest Inventory. For. Sci. 55: 480$376 \quad 493$.

377 FMI. 2001. Janikan päivän myrsky Pyryn päivän myrskyä voimakkaampi [online]. Available 378 from http://ilmatieteenlaitos.fi/tiedote/1006239658 [accessed 11.12.2017].

379 Gallant, J.C., and Wilson, J.P. 2000. Primary topographic attributes. In Terrain analysis:

380 Principles and applications. Edited by J.P. Wilson and J.C. Gallant. Wiley, New York pp. $381 \quad 51-85$.

382 Gregow, H., Laaksonen, A., and Alper, M.E. 2017. Increasing large scale windstorm damage in 383 Western, Central and Northern European forests, 1951-2010. Sci. Rep. 7: 46397.

384 Guisan, A., Weiss, S.B., and Weiss, A.D. 1999. GLM versus CCA spatial modeling of plant 385 species distribution. Plant Ecol. 143: 107-122. 
Hijmans, R.J. 2016. raster: Geographic data analysis and modeling. R package. https://CRAN.Rproject.org/package=raster. Version 2.5-8.

Honkaniemi, J., M. Lehtonen, H. Väisänen, and H. Peltola. 2017. Effects of wood decay by Heterobasidion annosum on the vulnerability of Norway spruce stands to wind damage: a mechanistic modelling approach. Can. J. For. Res. 47: 777-787.

391 Hosmer, D.W., Lemeshow, S., and Sturdivant, R.X. 2013. Applied logistic regression. 3rd ed. 392 John Wiley \& Sons, New York.

393 Ihalainen, A., and Ahola, A. 2003. Pyry- ja Janika-myrskyjen aiheuttamat puuston tuhot.

394 Metsätieteen aikakauskirja 3: 385-401.

395 Jalkanen, A., and U. Mattila. 2000. Logistic regression models for wind and snow damage in 396 northern Finland based on the National Forest Inventory data. For. Ecol. Manage. 135: 315$397 \quad 330$.

398 Jung, C., and Schindler, D. 2016. Modelling monthly near-surface maximum daily gust speed 399 distributions in Southwest Germany. Int. J. Climatol. 36: 4058-4070.

400 Kalela, E. K. 1949. Männiköiden ja kuusikoiden juurisuhteista I (On the horizontal roots in pine 401 and spruce stand I. In Finnish, summary in English). Acta For. Fenn. 57: 1-79.

402 Kamimura, K., Gardiner, B., Dupont, S., Guyon, D., and Meredieu, C. 2016. Mechanistic and 403 statistical approaches to predicting wind damage to individual maritime pine (Pinus 404 pinaster) trees in forests. Can. J. For. Res. 46: 88-100. 
405 Laiho, O. 1987. Susceptibility of forest stands to windthrow in southern Finland (in Finnish, 406 summary in English). Folia For. 706: 1-24.

407 Lantmäteriet. 2017. Fakta om laserskanning [online]. Available from

408 https://www.lantmateriet.se/sv/Kartor-och-geografisk-information/Hojddata/Fakta-om-

$409 \quad$ laserskanning [accessed 14.8.2017].

410 Lindroth, A., Lagergren, F., Grelle, A., Klemedtsson, L., Langvall, O., Weslien, P., and Tuulik,

411 J. 2009. Storms can cause Europe-wide reduction in forest carbon sink. Global Change Biol.

$412 \quad$ 15: $346-355$.

413 Lohmander, P., and Helles, F. 1987. Windthrow probability as a function of stand characteristics 414 and shelter. Scand. J. For. Res. 2: 227-238.

415 Mattila, U. and Nuutinen, T. 2007. Assessing the incidence of butt rot in Norway spruce in $416 \quad$ Southern Finland. Silva Fenn. 41: 29-43.

417 NLS. 2017a. Elevation model 2 m [online]. Available from http://maanmittauslaitos.fi/en/maps418 and-spatial-data/expert-users/product-descriptions/elevation-model-2-m [accessed $419 \quad 14.8 .2017]$

420 NLS. 2017b. Elevation model $10 \mathrm{~m}$ [online]. Available from http://maanmittauslaitos.fi/en/maps421 and-spatial-data/expert-users/product-descriptions/elevation-model-10-m [accessed 422 14.8.2017]. 
423 Nykänen, M., Peltola, H., Quine, C., Kellomäki, S., and Broadgate, M. 1997. Factors affecing 424 snow damage of tree with particular reference to European conditions. Silva Fenn. 31: 193213.

426 Pebesma, E.J. 2004. Multivariable geostatistics in S: the gstat package. Comput. Geosci. 30: $427 \quad 683-691$.

428 Peltola, H., S. Kellomäki, H. Väisänen, and V. P. Ikonen. 1999. A mechanistic model for 429 assessing the risk of wind and snow damage to single trees and stands of Scots pine, $430 \quad$ Norway spruce, and birch. Can. J. For. Res. 29: 647-661.

431 Peltola, H., S. Kellomäki, A. Hassinen, and M. Granander. 2000. Mechanical stability of Scots 432 pine, Norway spruce and birch: an analysis of tree-pulling experiments in Finland. For. 433 Ecol. Manage. 135: 143-153.

434 Pfeffermann, D., Skinner, C.J., Holmes, D.J., Goldstein, H., and Rasbash, J. 1998. Weighting for 435 unequal selection probabilities in multilevel models. J. R. Stat. Soc. Series B 60: 23-40.

436 Quine, C.P. and White, I.M.S. 1998. The potential of distance-limited topex in the prediction of $437 \quad$ site windiness. Forestry 71: 325-332.

438 Rabe-Hesketh, S., and Skrondal, A. 2006. Multilevel modelling of complex survey data J. R. 439 Stat. Soc. Series A 169: 805-827.

440 Reyer, C.P.O., Bathgate, S., Blennow, K., Borges, J.G., Bugmann, H., Delzon, S., Faias, S.P., 441 Garcia-Gonzalo, J., Gardiner, B., Gonzalez-Olabarria, J.R., Gracia, C., Hernández, J.G., 442 Kellomäki, S., Kramer, K., Lexer, M.J., Lindner, M., van der Maaten, E., Maroschek, M., 
Muys, B., Nicoll, B., Palahi, M., Palma, J.H., Paulo, J.A., Peltola, H., Pukkala, T., Rammer, W., Ray, D., Sabaté, S., Schelhaas, M., Seidl, R., Temperli, C., Tomé, M., Yousefpour, R., Zimmermann, N.E., and Hanewinkel, M. 2017. Are forest disturbances amplifying or canceling out climate change-induced productivity changes in European forests? Environ. Res. Lett. 12: 034027.

448

449

450

Saarinen, N., Vastaranta, M., Honkavaara, E., Wulder, M.A., White, J.C., Litkey, P., Holopainen, M., and Hyyppä, J. 2016. Using multi-source data to map and model the predisposition of forests to wind disturbance. Scand. J. For. Res. 31: 66-79.

SAS Institute Inc. 2017. Base SAS® 9.4 Procedures Guide. SAS Institute Inc., Cary, NC.

Schelhaas, M., Nabuurs, G., and Schuck, A. 2003. Natural disturbances in the European forests in the 19th and 20th centuries. Global Change Biol. 9: 1620-1633.

Schindler, D., Grebhan, K., Albrecht, A., and Schönborn, J. 2009. Modelling the wind damage probability in forests in Southwestern Germany for the 1999 winter storm 'Lothar'. Int. J. Biometeorol. 53: 543-554.

Schindler, D., Grebhan, K., Albrecht, A., Schönborn, J., and Kohnle, U. 2012. GIS-based estimation of the winter storm damage probability in forests: a case study from BadenWuerttemberg (Southwest Germany). Int. J. Biometeorol. 56: 57-69.

Schmidt, M., Hanewinkel, M., Kändler, G., Kublin, E., and Kohnle, U. 2010. An inventorybased approach for modeling single-tree storm damage - experiences with the winter storm of 1999 in southwestern Germany. Can. J. For. Res.40: 1636-1652. 
463 Scott, R.E. and Mitchell, S.J. 2005. Empirical modelling of windthrow risk in partially harvested 464 stands using tree, neighbourhood, and stand attributes. For. Ecol. Manage. 218: 193-209.

465 Seidl, R., Schelhaas, M., Rammer, W., and Verkerk, P.J. 2014. Increasing forest disturbances in 466 Europe and their impact on carbon storage. Nat. Clim. Change 4: 806-810.

467 Seidl, R., Thom, D., Kautz, M., Martin-Benito, D., Peltoniemi, M., Vacchiano, G., Wild, J., 468 Ascoli, D., Petr, M., Honkaniemi, J., Lexer, M.J., Trotsiuk, V., Mairota, P., Svoboda, M., 469 Fabrika, M., Nagel, T.A., and Reyer, C.P.O. 2017. Forest disturbances under climate $470 \quad$ change. Nat. Clim. Change 7: 395-402.

471 Suvanto, S., Henttonen, H.M., Nöjd, P., and Mäkinen, H. 2016. Forest susceptibility to storm 472 damage is affected by similar factors regardless of storm type: Comparison of thunder storms and autumn extra-tropical cyclones in Finland. For. Ecol. Manage. 381: 17-28.

474 Swisstopo. 2017. Lidar data acquisition [online]. Available from 475 https://www.swisstopo.admin.ch/en/knowledge-facts/geoinformation/lidar-data.html $476 \quad$ [accessed 14.8.2017].

477 Tomppo, E., Heikkinen, J., Henttonen, H.M., Ihalainen, A., Katila, M., Mäkelä, H., Tuomainen, 478 T., and Vainikainen, N. 2011. Designing and conducting a forest inventory - case: 9th 479 National Forest Inventory of Finland. Managing Forest Ecosystems 21, Springer, Dortrecht.

480 Valinger, E., and Fridman, J. 2011. Factors affecting the probability of windthrow at stand level 481 as a result of Gudrun winter storm in southern Sweden. For. Ecol. Manage. 262: 398-403. 
482 Venäläinen, A., Laapas, M., Pirinen, P., Horttanainen, M., Hyvönen, R., Lehtonen, I., Junila, P., 483 Hou, M., and Peltola, H.M. 2017. Estimation of the high-spatial-resolution variability in 484 extreme wind speeds for forestry applications. Earth Syst. Dynam. 8: 529-545.

485 Whitney, R. D., R. L. Fleming, K. Zhou, and D. S. Mossa. 2001. Relationship of root rot to black 486 spruce windfall and mortality following strip clear-cutting. Can. J. For. Res. 32: 283-294.

487 Zubizarreta-Gerendiain, A., Pellikka, P., Garcia-Gonzalo, J., Ikonen, V.P. and Peltola, H. 2012. 488 Factors affecting wind and snow damage of individual trees in a small management unit in 489 Finland: assessment based on inventoried damage and mechanistic modelling. Silva Fenn. $490 \quad$ 46: 181-196. 
492 Table 1. Details about the storm damage data: number of trees, DBH $(\mathrm{cm})$ and tree height $(\mathrm{m})$ in 493 damaged and undamaged trees for different species.

\begin{tabular}{llll} 
& No damage & Damage & All \\
\hline Number of trees & & & \\
All species & 16375 & 202 & 16577 \\
Scots pine & 6447 & 80 & 6527 \\
Norway spruce & 6793 & 111 & 6904 \\
Broad-leaved & 3135 & 11 & 3146 \\
DBH (mean \pm st. deviation) & & & \\
All species & $20.07 \pm 9.35$ & $23.98 \pm 9.89$ & $20.11 \pm 9.37$ \\
Scots pine & $20.64 \pm 8.83$ & $21.42 \pm 7.98$ & $20.65 \pm 8.82$ \\
Norway spruce & $21.45 \pm 9.46$ & $26.88 \pm 10.30$ & $21.54 \pm 9.50$ \\
Broad-leaved & $15.87 \pm 8.93$ & $13.36 \pm 5.04$ & $15.86 \pm 8.92$ \\
Height (mean \pm st. deviation) & & & \\
All species & $16.34 \pm 5.85$ & $18.91 \pm 5.87$ & $16.37 \pm 5.86$ \\
Scots pine & $15.57 \pm 5.47$ & $16.56 \pm 4.90$ & $15.58 \pm 5.46$ \\
Norway spruce & $17.47 \pm 5.92$ & $21.05 \pm 5.85$ & $17.53 \pm 5.93$ \\
Broad-leaved & $15.47 \pm 6.06$ & $14.54 \pm 3.21$ & $15.47 \pm 6.05$ \\
\hline
\end{tabular}


495 Table 2. Description of variable groups and independent variables used in the final models. In 496 categorical variables the class mentioned first is used as the reference class in the models (i.e. 497 parameters are estimated only to the other classes).

\begin{tabular}{|c|c|c|c|}
\hline & data type & units/classes & data source \\
\hline \multicolumn{4}{|l|}{ TREE } \\
\hline Species group (SPECIES) & categorical & conifer, deciduous & NFI9 \\
\hline Tree height (HEIGHT) & numeric & $\mathrm{cm}$ & NFI9 \\
\hline \multicolumn{4}{|l|}{ STAND } \\
\hline $\begin{array}{l}\text { Cutting in the last } 10 \text { years } \\
\text { (CUTTYPE) }\end{array}$ & categorical & $\begin{array}{l}\text { none or thinning, regeneration } \\
\text { cutting }\end{array}$ & $\begin{array}{l}\text { NFI9, storm } \\
\text { data }\end{array}$ \\
\hline Decay in stand & categorical & absent, present & NFI9 \\
\hline $\begin{array}{l}\text { New open area in wind direction } \\
\text { (OPENAREA) }\end{array}$ & categorical & absent, present & storm data \\
\hline \multicolumn{4}{|l|}{ TOPO2 } \\
\hline Slope steepness (SLOPE) & numeric & degrees & DEM2 \\
\hline \multicolumn{4}{|l|}{ TOPO10 } \\
\hline Slope steepness (SLOPE10) & numeric & degrees & DEM10 \\
\hline
\end{tabular}


500 Table 3. Parameters used for scaling the continuous variables in the final models. Scaling to 501 mean 0 and standard deviation 1 were calculated as $X_{\text {scaled }}=(X-\mu) / \sigma$.

\begin{tabular}{lcc} 
Variable & $\mu$ & $\sigma$ \\
\hline $\log ($ HEIGHT $)$ & 2.72 & 0.43 \\
$\log ($ SLOPE +0.1$)$ & 1.24 & 0.82 \\
$\log ($ SLOPE $10+0.1)$ & 0.58 & 1.55 \\
\hline
\end{tabular}


503 Table 4. Comparison of models with AIC, difference in AIC compared to the best model 504 ( $\triangle \mathrm{AIC})$, AIC weights $\left(w_{i}\right)$ and AUC. For the explanations of the variable groups, see Table 2.

\begin{tabular}{lcccc} 
Model & AIC & $\Delta$ AIC & $w_{i}$ & AUC \\
\hline TREE + STAND + TOPO2 & 1551.58 & 0.00 & 0.48 & 0.70 \\
TREE + STAND + TOPO2 + TOPO10 & 1553.44 & 1.86 & 0.19 & 0.70 \\
TREE + STAND & 1554.22 & 2.64 & 0.13 & 0.70 \\
TREE & 1554.37 & 2.79 & 0.12 & 0.66 \\
TREE + STAND + TOPO10 & 1554.92 & 3.34 & 0.09 & 0.70 \\
STAND & 1576.76 & 25.18 & 0.00 & 0.62 \\
TOPO2 & 1577.12 & 25.54 & 0.00 & 0.51 \\
TOPO10 & 1579.51 & 27.93 & 0.00 & 0.53 \\
\hline
\end{tabular}


Table 5. The fixed effect results and the covariance parameter estimates for the random effects (clusters and plots nested within clusters) of the best model. For the explanations of the fixed effects variables, see Table 2. Note that continuous variables were scaled before model fitting, parameters used in scaling can be found in Table 3.

\begin{tabular}{|c|c|c|c|c|c|}
\hline Fixed effects & Estimate & St.Error & DF & $\mathrm{t}$ value & $\operatorname{Pr}>|t|$ \\
\hline Intercept & -9.92 & 0.36 & 266 & -27.95 & $<.001$ \\
\hline \multicolumn{6}{|l|}{ TREE } \\
\hline SPECIES $_{\text {deciduous }}$ & -1.32 & 0.60 & 262 & -2.19 & 0.030 \\
\hline $\log (\mathrm{HEIGHT})$ & 0.55 & 0.17 & 16303 & 3.23 & 0.001 \\
\hline SPECIES $_{\text {deciduous }}: \log ($ HEIGHT $)$ & -0.76 & 0.26 & 16303 & -2.87 & 0.004 \\
\hline \multicolumn{6}{|l|}{ STAND } \\
\hline OPENAREA & 0.93 & 0.25 & 154 & 3.67 & $<.001$ \\
\hline CUTTING $_{\text {regeneration }}$ & 1.17 & 0.51 & 71 & 2.29 & 0.025 \\
\hline DROT & 0.84 & 0.42 & 57 & 2.01 & 0.050 \\
\hline \multicolumn{6}{|l|}{ TOPO2 } \\
\hline $\log (\mathrm{SLOPE})$ & -0.36 & 0.15 & 16303 & -2.48 & 0.013 \\
\hline Random effects & Estimate & St. Error & & & \\
\hline Cluster & 2.68 & 0.79 & & & \\
\hline Plot (Cluster) & 34.00 & 5.27 & & & \\
\hline
\end{tabular}



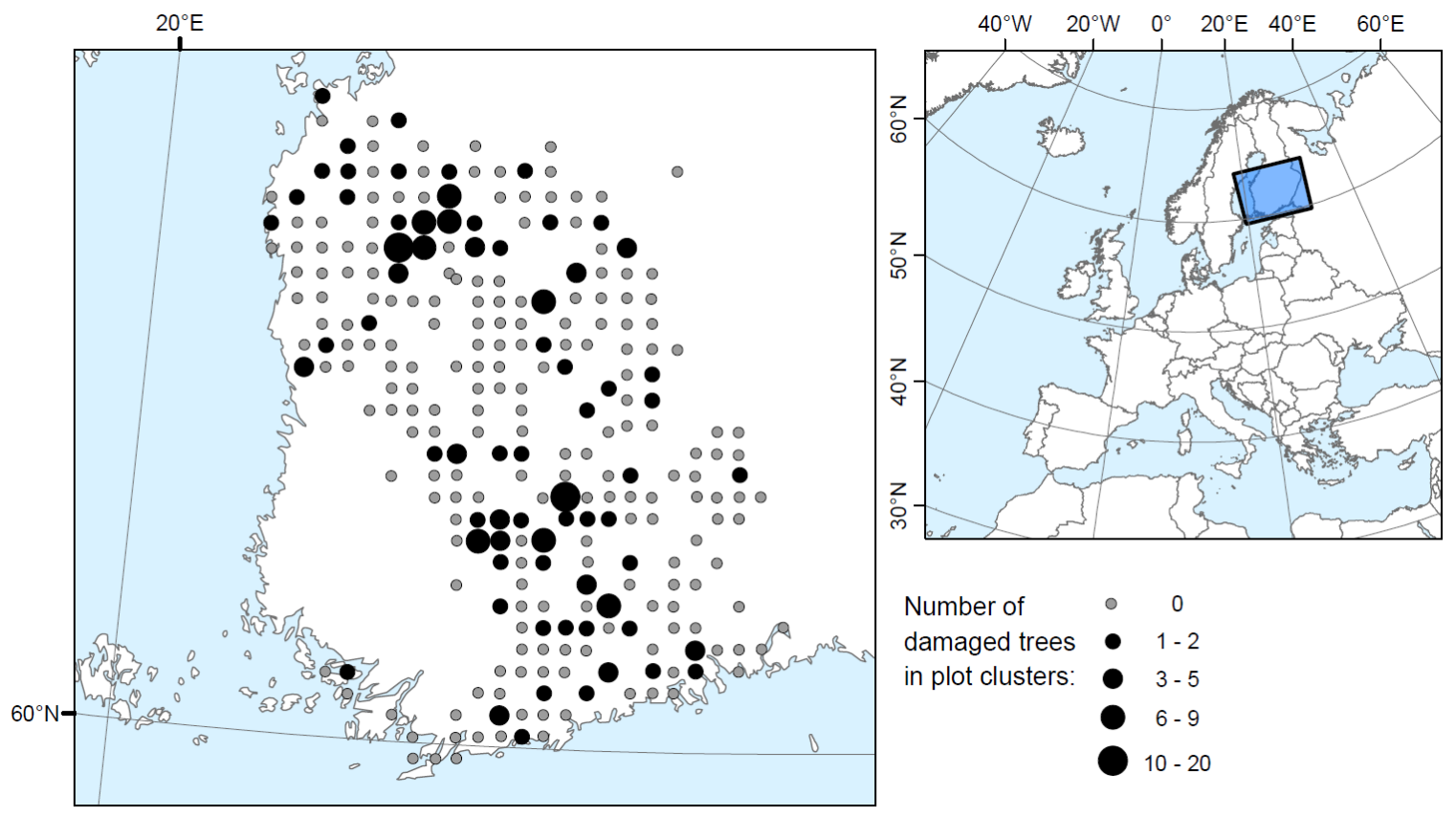

Figure 1. Map of the study area. The NFI9 plots where the storm damage data is collected from are shown in the figure on the left, the size of the dot refers to number of damaged trees in each plot cluster. 

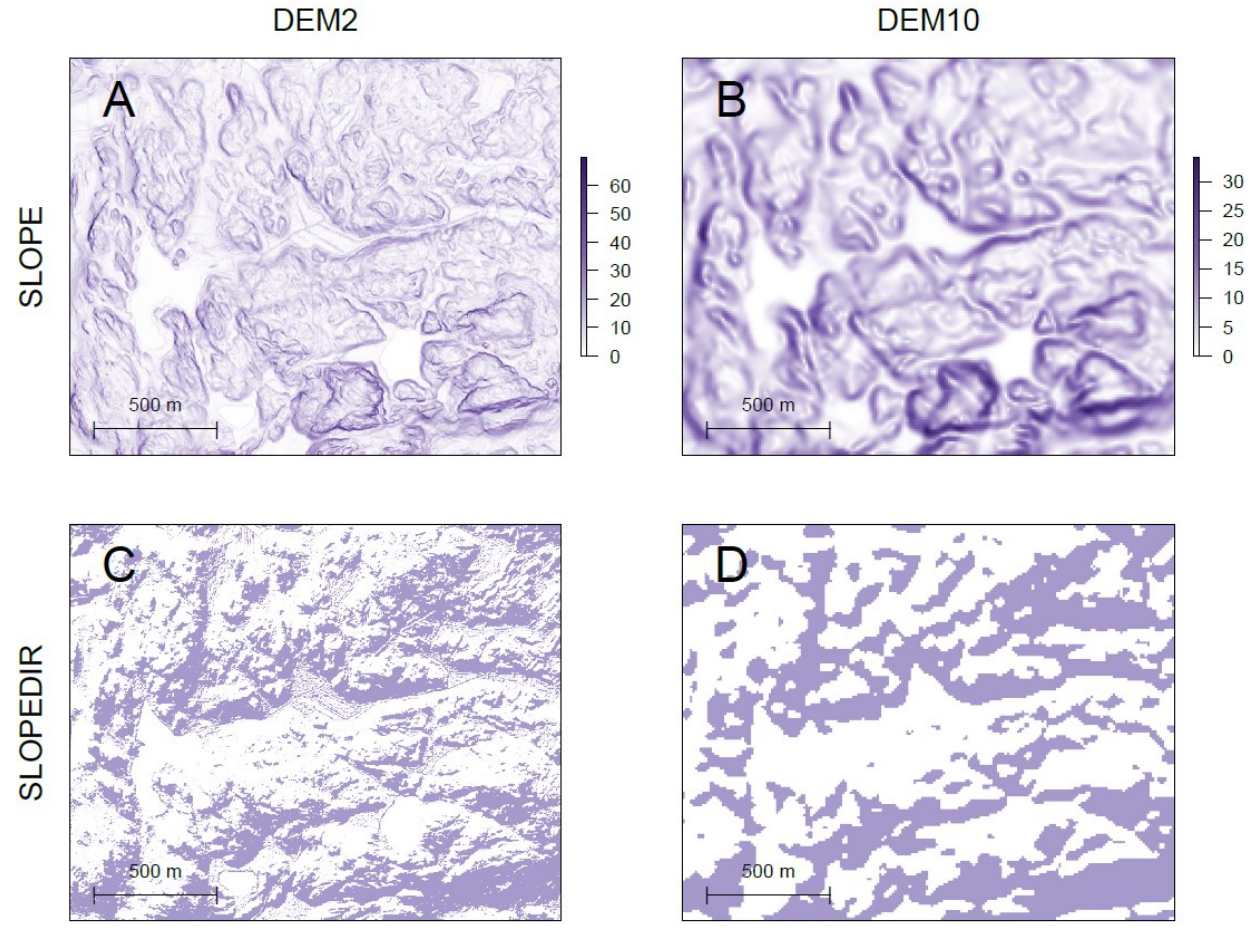

Figure 2. Examples of the topography variables calculated for the same area from digital elevation models (DEM) with different resolutions: Slope steepness (degrees) calculated from 2 meter resolution DEM (DEM2) (A) and 10 meter resolution DEM (DEM10) (B), slope direction, with shelter side shown as shadowed, calculated from DEM2 (C) and DEM10 (D). Top of the figures are towards north. 


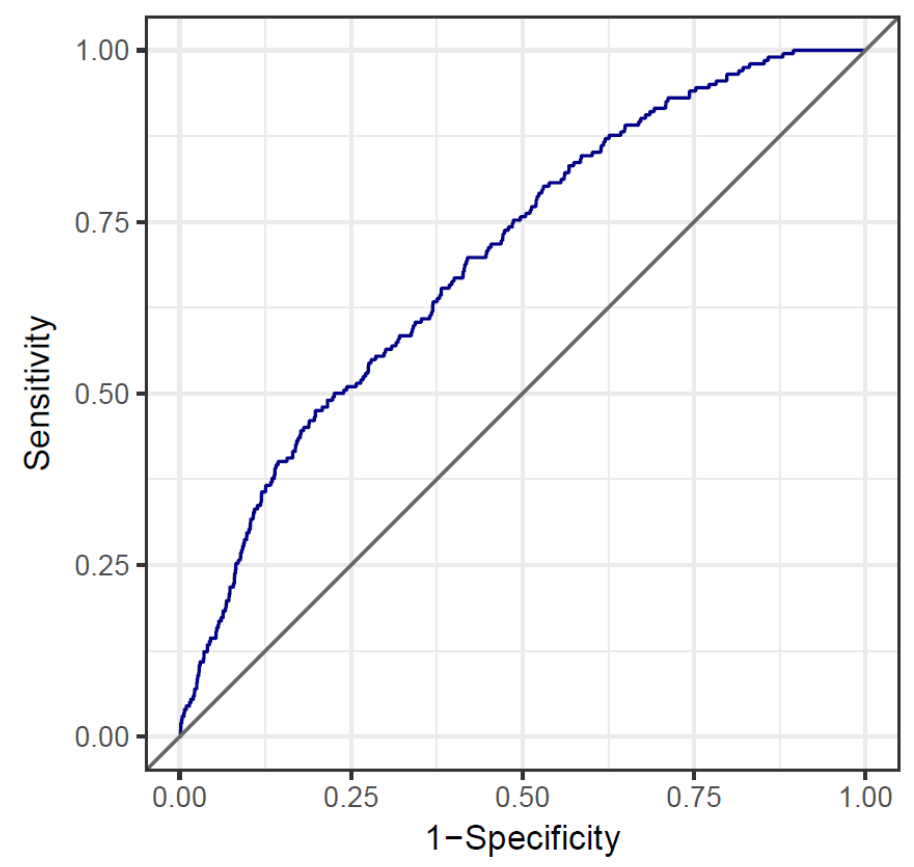

Figure 3. ROC curves of the model with the lowest AIC. The curve illustrates the discrimination ability of the model and shows the model's sensitivity (true positive rate) and 1-specificity (false positive rate) with different classification thresholds. Area under the curve $(A U C)=0.70$. 